\title{
A Strategic Analysis of Product Recalls: The Role of Moral Degradation and Organizational Control
}

\author{
Yadong Luo \\ University of Miami, USA
}

ABSTRACT Although product recalls are neither new nor unique to China, China bears much of the bitter criticism from the media and negative reactions from the public. This essay discusses the reasons behind recalls from a moral degradation perspective, grounded in the larger framework of anomie theory. While making remarkable cconomic progress, China is also moving toward a society with degraded moral standards. This moral degradation propels illicit and immoral business practices. This essay further presents an analysis of recall from the organizational control perspective, tackling the issue of how safety and quality problems damage a firm's long-term corporate credibility, legitimacy, trust and governance in a competitive environment. Strategic repercussions of recalls include impairing capability building, organizational learning and resource allocation. The essay ends with a call for action by the Chinese government, firms and management researchers to address and further understand this complex issue.

KEYWORDs product recall, moral degradation, organizational control

\section{INTRODUCTION}

After more than a year of massive toy recalls, tainted toothpaste scares and poisonous pet food incidents, consumers around the globe are becoming increasingly reluctant to buy China-made goods. This should not be surprising because product quality and safety-related issues were commonplace in China long before they were publicized by Western media. During economic and social transformation, societies tend to become increasingly devoid of morals (Harvey, 1999), often allowing illicit and immoral business practices to prevail. If not effectively curbed, however, these practices will harm not only consumer well-being and collective credibility of Chinese firms, but also economic growth of the society as a whole. For legitimate businesses competing in international or domestic markets, it is important to comprehend the severe consequences of quality and safety-related recalls and devise strategic approaches to avoid their occurrences. This essay analyses the 
product recall issue from a strategic perspective by explaining how it is related to the problem of moral degradation in a transforming society and the consequences of product recalls to the strategic development of the firm.

\section{A STRATEGIC ANALYSIS OF PRODUCT REGALLS}

Safety and quality-related recall is, of course, by no means exclusive to Chinese products. Nokia's mobile phones had overheating problems caused by batteries manufactured by the supplier Matsushita. In 2006, Dell recalled more than 4 million PCs worldwide, costing an estimated $\$ 300 \mathrm{~m}$. Lenovo, Dell, Apple and Toshiba together recalled millions of Sony-made lithium-ion batteries in laptops sold worldwide (Campbell \& Moltzen, 2006).

The severity and scale of safety-related recalls have recently been magnified due to heightened customer awareness, increased global and domestic competition and more stringent product safety legislations in advanced markets, particularly, in the USA, the EU and Japan. For example, the new European Product Safety Legislation, effective from November 2005, regulates that manufacturers are responsible for informing the authorities and consumers of any potential risk to consumers (Schepel, 2006). Additional reasons for this magnification of recalls might include the fear of China's manufacturing and exporting power in the minds of Western protectionists and the lack of experience and education of Chinese producers, especially medium and small suppliers who are new to both global competition and living up to international rules and standards. In addition, emotions ran high when the volume of recalls (especially with toys) reached more than 20 million units from one company alone and when the safety issues involved children, a vulnerable group about whom adult consumers are particularly concerned.

It is interesting, as acknowledged in the letter of apology by Mattel, that the 'vast majority of the products that were recalled were the result of a design flaw in Mattel's design, not through a manufacturing flaw in China's manufacturers' (Businessline, 2007). While this indicates that US firms are partly responsible for the errors that result in recalls, it also provides a context for assessing the subsequent vehement accusations aimed at China, as many in the protectionist crowd used these events for their own narrow and private purposes. However, this is not to say that China is blameless in this situation (far from it).

That being said, China bears the brunt of much of the bitter and serious consequences of such recalls. Consumer confidence has been dented by massive recalls; customers and users are paying more attention to where toys are produced. The 'Made in China' label, when stereotypically associated with poor safety and quality, could further impair Chinese exports and economic growth. Many Western companies are looking at the possibility of sourcing more toys from Europe rather than China. Thus, for some time yet, 'Made in China' may be more an insult than an endorsement. Food and toy recalls have created an image 
problem for many other Chinese exporters and dealt a serious setback to mainland brands. Several internationally recognizable brands, such as Lenovo (PCs), Tsingtao (brewery), Haier (appliances), Huawei (telecoms) and Chery (automobiles) have launched marketing campaigns to build their names globally. However, for better or worse, the fortunes of all of these companies may now be tied to the image of Chinese products and the efforts to clean up China's reputation. With hundreds of products on the international market, a product recall and its related high-profile lawsuit or a potential class action suit are events that can destroy a brand's reputation, even one that has been carefully constructed through years of marketing and customer service.

\section{Moral Degradation as a Possible Explanation of Product Recall}

Consistently, and whether justified or not, manufacturers are seen as the main defendants, held directly accountable for recalls. However, there are several broader factors that share a portion of this responsibility. These include: (i) the weak legislation and lax enforcement on product liability in China; (ii) increasing cost cutting pressure; (iii) the growth of underground 'black heart' factories; (iv) the premature subcontractor system in sharing legal liabilities; (v) the lack of effective government supervision in product safety; (vi) ubiquitous counterfeits and ineffective public and government resistance against counterfeits; and (vii) rampant corruption, including bribery by defective product manufacturers to get government controlled, quality-related licenses or certificates. These are all symptoms of a more fundamental problem that may be the root of all such ills. Below, I propose a possible root cause of the problems that was manifested in the lack of attention to product quality and safety by some or perhaps many manufacturers.

I propose 'moral degradation', a neglected view, as an alternative and an additional possible underlying explanation for product recalls. Unequivocally, China has been remarkable in making economic progress, which is attributed to market oriented reforms, heightened competition in deregulated sectors, continued improvement in productivity and successful utilization of foreign direct investment. However, in the midst of this exciting progress and development, China also is moving toward a society with weakened morals, i.e., the society's progressive loss or weakening of right morality and ethics that have prevailed in the Chinese tradition (Harvey, 1999). Tam (2002) characterizes the contemporary business environment in China as rife with corruption, stock market manipulation, tax cheating, fraudulent dealings, all manner of plundering of state assets and disregard for shareholders' rights. Harvey (1999) concluded that the development of business ethics and professional morality had not kept pace with market reforms in China and that traditional Confucian notions of commercial ethics, which were long-established in 'old China', had seriously deteriorated. In fact, 'The Book of Rites', by Confucius (written sometime between 471-221 BC), emphasized 
commercial ethics, including forbidding cheating or the sale of inferior products as well as honoring contractual and regulatory systems for governing commercial behaviour. Similarly, Husters (2003) stated that systematic corruption in China has seeped into every aspect of the political, economic and moral spheres, giving rise to serious social inequalities at every level. As markets have expanded, professional morality has weakened, the sense of social responsibility dimmed and the phenomenon of money worship has grown. Redfern and Crawford (2004) demonstrate that Chinese managers are less idealistic, less concerned with humanitarianism and more concerned with self-interest and economic considerations such as profit than their Western counterparts. Wright, Szeto, and Lee (2003) found that many executives in China downplayed the harmful effect of corruption and bribery on China's image. Finally, Chan, Cheng, and Szeto (2002) show that less ethical or more morally degraded Chinese business executives tend to be younger and that a greater number of their less ethical and guanxi (interpersonal relationship) oriented respondents were employed by privately owned enterprises.

The moral degradation view is consistent with the premise of institutional anomic theory (Durkheim, 1966; Merton, 1968; Messner \& Rosenfeld, 1997; Rosenfeld \& Messner, 1997). This theory argues that cultural and social drivers result in conditions in which pressures for goal achievement through any means legitimate or not - displace normative control mechanisms. Durkheim (1966) assumed that institutional and cultural changes associated with modernization encouraged a decline of traditional social controls based on family and communal relationships, a resultant weakening of norms and, in turn, increased deviance. Merton (1968) defined anomie as a condition of normlessness and social disequilibrium where the rules once governing conduct have lost their savour and force. The theory also suggests that when a social system inhibits culturally valued goal achievement, it incubates a greater propensity to choose deviant means to achieve certain desirable ends. In China today, economic dominance, or yi qie xiang qian kan (all but money), has already become the prevalent social value and institutional form. Under this circumstance, economic goals are assigned high priority in comparison to non-economic or social goals, and the claims of economic roles are typically honoured at the expense of non-economic roles when conflicts occur. Social standing also tends to depend more on the performance of economic roles than of social roles. Furthermore, the calculating, utilitarian logic of the marketplace penetrates other institutional realms.

Moral degradation, along with extraordinarily high social injustice and its derived wealth disparity, has made the society virtuously ill and ethically apathetic. Congruent with the anomie theory arguing that multidrivers underlie normlessness, moral degradation in China is not only triggered by the pragmatism that permeates throughout the society today, but also engendered by other economic, social, legal and political causes that serve as catalysts of this phenomenon, exerting a much more enduring and extensive influence which contaminates both the economy and 
society. Socictal moral degradation and ethical paralysis could significantly increase transaction costs, operational uncertainties and managerial difficulties in planning, organizing and implementing legitimate business activities. The institutional anomic theorists believe that normlessness can permeate the social structure of firms, exerting pressure on them to engage in nonconforming rather than conforming bchaviour to achieve performance goals, especially when firms face high competition or institutional barriers (Cullen, Parboteeah, \& Hoegl, 2004). Lack of moral guidance or normlessness provides fertile soil for the growth of the anomic pressures associated with market arrangements (Jensen, 2002). Firms in an anomic social environment deviate from normatively accepted mechanisms for achieving important outcomes such as sales and profit. In an anomic organizational context, pressure exists to take any path that leads to the achievement of performance goals, regardless of its acceptability or legitimacy. Martin, Cullen, Johnson, and Parboteeah (2007) recently demonstrated that perceived pressures in this type of local environment produce anomic strain and increase illicit activities such as bribery.

Product recall is in part reflective of moral degradation and normlessness. It is true that no company can achieve zero defects always. However, according to corporate illegality theory (Baucus, 1994; McKendall \& Wagner, 1997), massive recalls are symptomatic of more than a fundamental flaw in production and operational processes, but rather are reflective of a moral hazard in organizing such processes. Firms consistently offering hazardous products are blind to their social responsibility and their impact on public wellbeing and disregard disastrous consequences to others and even to themselves in the long run. This malfeasant behaviour is not only opportunistic, but in many cases illegal and criminal (Baucus \& Near, 1991; Luo, 2006). Of course, corporate illegality is not China specific. As Bapuji and Beamish $(2007,2008)$ and Beamish and Bapuji (2008) recently concluded, the number of defects related to design issues is far higher than those caused by manufacturing problems in China. Still, Chinese firms engaging in immoral activities may not feel guilty nor be fearful about what they have done because they often rely on guanxi based corruption or corrupted guanxi to safeguard themselves. Apathetic to unlawful, illicit and immoral conduct for selfish business interests indicates lack or loss of business morals.

With weakened moral standards, guanxi and corruption become intertwined. Immoral producers are often opportunistic with no guile (McKendall \& Wagner, 1997). When caught for violating product safety rules, some immoral managers may not be fearful, expecting to use their corrupted guanxi or guanxi based corruption to deter a governmentally instituted investigation or avoid material penalty by a regulatory or judiciary authority. As guanxi progressively intertwines with corruption, public perception changes from a tradition honoured culture to a corrupted rent secking practice. As moral degradation worsens, negative perceptions of guanxi increase. In this environment, it will be difficult to distinguish between guanxi and corruption. Under such conditions where illicit business practices are no longer 
portrayed as immoral and unethical by players, legal sanctions cannot eradicate product safety horrors.

\section{Organizational Control and Product Recall}

While moral degradation provides a basis to understand why product safety and standards are secondary to meeting product schedules and economic goals, it is not the only reason. Product recall is also the result of poor management and weak organizational control. Systematic and massive recalls indicate problematic, shortsighted leadership. Under such leadership, it is unlikely that a firm would have an innovative culture, efficient administration, internal control and productive collaboration across departments or divisions within a firm. Product recall tends to occur in the companies without safety programmes and without effective quality control. A design problem will result in an unsafe product irrespective of where it is manufactured, while a manufacturing defect arises because of manufacturer errors or negligence. In poorly managed firms, management teams are unlikely to make safety and quality an important and highly visible objective. There is often the absence of a formal policy statement, or when a statement is present, its implementation is not enforced. The elements of a strong and successful product safety and liability prevention programme require top management's commitment to the programme, followed by a company-wide safety training and awareness as well as a specialized safety team drawn from all involved departments. Implementation and documentation of all necessary procedures and standard practices require effective leadership and a routinized culture to foster such activities. Furthermore, there must be a system for measurement, correction and status reporting, as well as a regular audit of programme effectiveness. Unsafe goods producers lack such internal control and organizational governance.

From a short-term perspective, selling unsafe products, domestically or internationally, can help reduce the costs of a specific transaction. However, in the long term, the total organizational losses may outweigh the short-term gains from a specific transaction. Massive product recall indicates poor governance within the firm, manifested in resource misallocation, capability building deterrence and lack of predictability. In a competitive environment, firm growth depends on its dynamic capabilities such as organizational learning, knowledge upgrading, continuous innovation and innovative corporate culture (Teece, Pisano, \& Shuen, 1997). In an organizational environment where corporate integrity and product integrity are not respected, these dynamic capability mechanisms are unlikely to be fostered and nourished. As an evolutionary hazard in the long term, repeated product recalls obstruct firm growth and business development.

Contractual governance has long been weak in China and even weaker in subcontracting manufacturing. Parties often do not include well-specified terms and clauses in an agreement or contract (Luo, 2006). This non-specification and its 
related uncertainty, while offering flexibility to the manufacturer, create costs and difficulties in subsequent strategic planning, flexibility maintenance and strategy implementation in a constantly changing environment for the buyer. Under standard contract manufacturing, a supplier or manufacturer has the highest payoff when it can reduce costs by lowering the quality of the goods it produces. A buyer or distributor has the highest payoff when it purchases goods that meet its quality standards without having to expend resources to verify this. Neither manufacturer nor buyer knows in advance what its counterpart will do and, therefore, each bases its own action on what it expects of the other. Because of these reasons, along with the fact that the rule of commercial law has traditionally been ineffective in China, contractual governance in most Sino-foreign manufacturing alliances or subcontracting is weak. Due to the Wal-Mart effect (using its enormous buying power to purchase in bulk and negotiate cheaper prices from suppliers), many Chinese suppliers have incentives to cut costs by substituting cheaper materials or components.

The problem is compounded by the continued appreciation of the yuan against the dollar and the upward trend of energy and raw material prices in China and around the world. The increasing production costs for Chinese exporters or outsourcing providers pressure them to find lower cost materials and lessen quality standards. Limited specifications of contractual terms concerning production standards, low contractual obligations and weak legal penalties cannot forestall producers and suppliers from conducting their wrongdoing (Luo, 2005). The reluctance of foreign importers or distributors to expend resources in verifying offshore manufacturing processes makes quality and safety-related recalls more likely to occur (Lyles, Flynn, \& Frohlich, 2008).

Trust is an important complement for contractual governance in interfirm exchanges (Luo, 2002). However, product recall significantly impairs trust. Problems in product quality and safety are likely to occur in exchanges between opportunistic, short-sighted actors. Trust building necessitates forward thinking and long-term commitment to specific relationships and to repeated transactions (Granovetter, 1985). Relational commitment is accumulative, time consuming and often joined with unilateral sacrifices for the common interest of the partners in a relationship (Luo, 2002). Product recall damages unilateral and bilateral efforts in building interorganizational trust. Confident expectations and a willingness to be vulnerable are critical components of trust (Rousseau, Sitkin, Burt, \& Camerer, 1998 , p. 395). Trust comprises the intention to accept vulnerability based on positive expectations of the intentions or behaviours of another. Product recall causes a confidence loss from more parties than the firm may expect. These parties include not only transacting members (c.g., partners, distributors, suppliers) but many others too, such as investors, creditors, legislators, regulators, advertising agencies, accounting and auditing firms as well as other public and professional service providers. Massive product recalls violate both contractual specifications 
and behavioural assumptions underlying trust. In the eyes of consumers, recall indicates organizational illness and operational deficiency. Credibility is an important resource that creates competitive advantage and distinguishes a firm from its rivals (Barney \& Hansen, 1994). Product recall and its underlying opportunistic behaviour precipitate dishonesty and dissipate credibility. When a firm is involved in such activities, other firms will perceive it as unreliable and will avoid conducting business with it (Gioia, Schultz, \& Corley, 2000). Dishonesty and unreliability thus destroy, rather than stimulate, business networks.

The illicit nature of massive recalls mirrors the lack of integrity at corporate, business and product levels. Adherence to the law and contract is a prerequisite for corporate reputation and trustworthiness. In an increasingly competitive environment, long-term relationships with suppliers, subcontractors and other firms affecting a firm's backward or forward value chain become fundamental. A break in such long-term relationships as a result of recall longitudinally hampers a firm's market reputation and competitive advantages.

\section{GALL FOR ACTIONS}

The time is ripe for actions by multiple parties to curb the current trend and restore confidence in Chinese contract manufacturing and China's national image. I call for actions by three parties: the Chinese government, firms and management researchers, who collectively should contribute to manage and understand this complex issue that affects not only the firms involved, but also the country as a whole and the people within the firms and the nation.

\section{A Call for Action by Chinese Government}

A broad answer to this question is that 'Made in China' products have to embody a higher flavour of innovation, brand reputation and customer responsiveness. It is also strategic for China to manufacture and export more mid-end and high-end products suitable for international markets (both developed and developing) and fewer low-end products that exhaust tremendous energy and natural resources and cause substantial pollution. A viable long-term direction is that Chinese firms have no choice but to enhance the VP (value-price) and PC (price-cost) ratios if they want to survive and thrive in an increasingly energy and resource expensive and ecologically stringent marketplace.

To fulfill this end, both governmental and corporate efforts are imperative. At the governmental level, regulatory agencies (e.g., the Ministry of Commerce, International Trade Promotion Commission, Commodity Inspection Bureau and Customs Office) and their provincial branches must play a greater role as effective facilitators, supervisors and coordinators in quality and safety control. Some of their new roles in this area include the following: 
1. Formulating the overall strategic plan that blueprints the goals, strategies and measures of China's internationalization encompassing trading (export and import), subcontracting (original equipment manufacturer, OEM, or original brand manufacturer, OBM), inward foreign direct investment (FDI; including mergers and acquisitions) and outward FDI (in developed and developing countries).

2. Developing specific manufacturing exporting programmes and policies for major industries, financially and institutionally encouraging Chinese firms to upgrade products and improve both quality and safety. In the long term, it is still realistic for many Chinese firms to participate in international competition based on cost and volume based advantages. This, however, must arise with increased VP and PC ratios as noted earlier. The cluster manufacturing model is one of such programmes, but the government must work more closely with these cluster bases in various provinces to guide and support their technological upgrading and safety control.

3. Adopting more effective yet indirect regulatory and administrative steps to overhaul product safety and quality. For example, production and export licenses or industrial membership may be granted only to those firms with a good record in and adequate capacity to manufacture quality and safe products. Those without such membership or licenses should be more rigorously inspected by related agencies. Both voluntary and mandatory inspection programmes should avail and apply to manufacturers requiring more sensitivity to safety (e.g., those in food industries). At the same time, government agencies must improve their transparency, efficiency and services. Several firms I visited in Guangdong, for example, complain that when these agencies are corrupted, the firms offering unsafe goods can still obtain inspection passes and export permissions from these agencies.

4. Rewarding high performing manufacturers and exporters. China should go beyond listing top manufactures and exporters based on revenue and should additionally recognize and reward those firms performing well in innovation, technology, brand reputation, corporate credibility, energy saving, environmental protection and quality improvement. This multidimensional index measures each firm's corporate, business and product level integrity at home and abroad. Meanwhile, poorly performing enterprises in these areas should be warned, penalized and ultimately terminated via financial and regulatory discipline.

5. Strengthening the supervisory and standard setting functions of industrial associations. Currently, those associations are still governmental (some of which were transformed from the previous industrial ministries), allowing them to administer and oversee product quality and safety on behalf of the central government. These associations should also work closely with product safety and commodity inspection agencies to set industry specific technical, 
supply, quality and safety standards for various products. Progressively, China needs to harmonize the different safety standards between domestic sales and exports and converge these standards with internationally accepted norms. Through these associations and safety control agencies, China may also build a nationwide information sharing system so that all related suppliers, manufacturers, exporters and government agencies will be instantly and frequently informed about global market demands for quality, new foreign government policies on safety and quality, new inspective and corrective measures called for by the Chinese government and the like.

In the wake of the product recall fiasco, many entities in the entire channel or supply chain should be on notice that risk management of production and outsourcing needs to be strengthened and maintained. After all, when consumers and shareholders sue for negligence and lost profits following safety problems and lower revenues, it won't be just Chinese manufacturers or subcontractors who are the main defendants. Original brand manufacturers, wholesale distributors, governmental agencies (e.g., Consumer Product Safety Commission in the USA; the National Commodity Inspection Bureau in China), judiciary departments, legal enforcement agencies, regional level governments and branches, among others, all share responsibility for product safety, inspection and correction. With the intense media bashing that the 'Made in China' tag underwent, China needs to project and live up to an image of a responsible trade partner genuinely interested in assuaging the quality and safety concerns of its consumers. Fulfilling this end requires tremendous efforts from the firm, industry, national and international levels.

On the positive side, 62 percent of mainland Chinese suppliers are increasing spending on quality control as a response to foreign buyers' increased concerns about quality and safety (PR Newswire, 2007). The Chinese government is also reportedly shutting down and revoking the business licenses of companies involved. After months of product recalls and fears over contaminated food imports, the US and Chinese governments reached a food and drug safety agreement on December 11, 2007, that will give US inspectors access to Chinese factories while assuring Chinese manufacturers continued access to the US market (Rhea, 2007). This agreement helps China recover, to some extent, from damaging publicity surrounding its products.

\section{A Call for Action by Firms}

In the end, it is up to Chinese firms to truly sharpen awareness of product quality and safety, fully understand the significant impact of product recall and undertake a strategic approach and corrective actions. Obviously, the best approach to protecting the firm from product recall is to ensure that an aggressive programme of product quality and safety prevention is in place. Such programmes not only 
help reduce accidents and increase safety, they also ultimately result in more competitive products. The phases for product safety and recall prevention programmes include policy development, programme design, ongoing evaluation and improvement.

As a first step in developing a prevention programme, corporate management must make safety an important and highly visible objective in the design, production and marketing of the company's product. At the very least, the manufacturers should establish a corporate safety policy and programme, identify personnel responsible for safety and require programme audits and documentation. From there, the programme should include company-wide safety training and awareness as well as a specialized safety team drawn from all involved company departments. Finally, there must be a system for measurement, corrective action and status reporting, as well as a regular audit of programme effectiveness.

Examining the design and anticipating potential problems during product use is an important and early measure in the above process. One viable mechanism for Chinese firms to prevent product recalls is to create a product integrity or safety committee to make and monitor safety-related decisions. The committee may be comprised of representatives from design, engineering, manufacturing, quality control, purchasing, advertising and marketing and legal and accounting departments. The committee can take a lead in: (i) establishing guidelines and criteria for the evaluation of product hazards; (ii) establishing criteria for wamings, labels and manuals; (iii) establishing guidelines for advertising, product brochures and other printed materials; and (iv) arranging for review of all product warranties, exculpatory clauses, disclaimers and liability release statements.

When relying on outside suppliers' components or materials, it is important to require each supplier's components, parts or materials to mark and code each unit to identify the manufacturer of such components. It is also critical to seek indemnification agreements from suppliers against the cost of recall or corrective action and any other losses relating to a recall of defective components or materials supplied by them.

In summary, what's needed is a strategy that deals with all stages of safety control and product recall, cutting across both multiple functions within the firm as well as moments in the recall process. Smith, Thomas, and Quelch (1996) provide suggestions on a firm's actions on the four functional areas of: (i) policy and planning; (ii) product development; (iii) communications; and (iv) logistics and information systems along three stages of problem discovery, during recall, and the aftermath and follow-up measures.

\section{A Call for Action by Management Researchers}

Product recall is merely a small window through which to see a broader, larger and troublesome problem for many Chinese firms - underdeveloped and under- 
enforced corporate integrity and business ethics and degrading morality at the societal level. More systematic investigations and sophisticated treatments of product recall are needed in future research. One important area of study is cross-level analysis to juxtapose the underlying tenets of institutional anomie theory with reports from individual Chinese firms regarding their experience with product recall. For example, are societal levels of moral degradation truly so great that all firms propagate behaviours defying hypernorms in corporate integrity, business integrity and product integrity? If yes, then does corporate reputation or legal punishment matter for correcting or averting product recalls? Is there a high correlation between product recalls, the country level corruption index and a society's anomie level? How are product recalls intertwined with corporate level bribery or corruption? What are the firm specific, or organizational level factors that can mute anomic drivers at the society level? The literature on corporate illegality and business ethics have documented that organizational determinants, such as corporate culture and values as well as compliance programmes and systems, can supersede external pressures for illicit activities (see Baucus, 1994; Baucus \& Near, 1991; Luo, 2005; McKendall \& Wagner, 1997). What types of organizational architecture could lead to fewer product recalls and reduce other corporate illegalities? China is an ideal setting to advance the institutional anomie theory, while product recall is a rich phenomenon to broaden strategic management research in general and organizational control in specific, using a cross-level lens that links societal, industrial and organizational forces within a unifying framework.

\section{NOTE}

The author would like to thank Professors Marshall Meyer, Anne Tsui and the anonymous reviewers for their helpful comments.

\section{REFERENCES}

Bapuji, H., \& Beamish, P. W. 2007. Toy recalls - Is China really the problem? Canada-Asia Commentary, 45: 1-9.

Bapuji, H., \& Beamish, P. W. 2008. How to avoid hazardous design flaws. Harvard Business Reviez, March 2008: 1-2.

Barney, J. B., \& Hansen, M. H. 1994. Trustworthiness as a source of competitive advantage. Strategic Management Joumal, 15: 175-190.

Baucus, M. 1994. Pressure, opportunity, and predisposition: A multivariate model of corporate illegality. Journal of Management, 10: 699-721.

Baucus, M., \& Near, J. 1991. Can illegal corporate behavior be predicted? An even history analysis. Academy of Management Journal, 34: 9-36.

Bcamish, P. W., \& Bapuji, H. 2008. Toy recalls and China: Emotion vs. cvidence. Management and Organization Revieze, 4: 197-209.

Businessline. 2007. Toys: Time for a better game plan. Chennai: Financial Times Information Limited, October 16. 
Campbell, S., \& Moltzen, E. F. 2006. Lenovo joins recall fray - Whitebook builders profit from notebook battery recall fallout. $\boldsymbol{C R N}$, October 2, Issue 1214: 48-49.

Chan, R. Y. K., Cheng, L. T. W., \& Szeto, R. W. F. 2002. The dynamics of guanxi and ethics for Chinese executives. Joumal of Business Ethics, 41: 327-336.

Cullen, J. B., Parbotccah, K. P., \& Hocgl, M. 2004. Cross-national differences in managers' willingness to justify ethically suspect behaviors: A test of institutional anomic theory. Academy of Management Journal, 47: 411-421.

Durkhcim, E. 1966. Suicide: A study in sociology. New York: Free Press.

Gioia, D. A., Schultz, M., \& Corley, K. G. 2000. Organizational identity, imagc, and adaptive instability. Academy of Management Review, 25: 63-81.

Granovetter, M. 1985. Economic action and social structurc: A theory of embeddedness. American Joumal of Sociology, 91: 481-510.

Harvey, B. 1999. Graccful merchants': A contemporary view of Chincse busincss cthics. Journal of Business Ethics, 20: 85-92.

Husters, T. 2003. China's neze order: Society, politics and economy in transition. Cambridge, MA: Harvard University Press.

Jensen, G. 2002. Institutional anomic and socictal variations in crimc: A critical appraisal. International Joumal of Sociology and Social Policy, 22(7/8): 45-74.

Luo, Y. 2002. Contract, cooperation and performancc in international joint ventures. Strategic Management Journal, 23: 669-694.

Luo, Y. 2005. An organizational perspective of corruption. Management and Organization Review, 1: 119-154.

Luo, Y. 2006. Opportunism in inter-firm exchanges in emerging markcts. Management and Organization Revieze, 2: 121-148.

Lylcs, M. A., Flynn, B. B., \& Frohlich, M. T. 2008. All supply chains don't flow through: Understanding supply chain issues in product recalls. Management and Organizational Revieve, 4: $167-182$.

McKendall, M., \& Wagncr, J., III. 1997. Motive, opportunity, choice, and corporate illegality. Organization Science, 8: 624-647.

Martin, K. D., Cullen,J. B., Johnson, J. L., \& Parbotccah, K. P. 2007. Deciding to bribc: A cross-level analysis of firm and homc country influences on bribery activity. Academy of Management Journal, 50: 1401-1422.

Mcrton, R. K. 1968. Social theory and social structure. Ncw York: Frce Prcss.

Messner, S., \& Roscnfeld, R. 1997. Political restraint of the market and levels of criminal homicide: A cross-national application of institutional-anomic thcory. Social Forces, 75: 1393-1416.

PR Nezeszeire. 2007. Ovcr sixty percent of mainland China exporters spending more on quality control - Global sourccs survey. Scptember 24.

Redfern, K., \& Crawford, J. 2004. An cmpirical investigation of the cthics position questionnaire in the Pcoplc's Republic of China. Journal of Business Ethics, 50: 199-2 10.

Rhca, S. 2007. US-Sino safcty pact callcd 'modest start'. Modem Healthcare, 37(50): 12-14.

Rosenfeld, R., \& Messner, S. F. 1997. Markets, morality, and an institutional anomic theory of crime. In N. Passas \& R. Agnew (Eds.), The future of anomie theory: 207-224. Boston, MA: Northeastern University Press.

Rousseau, D. M., Sitkin, S. B., Burt, R. S., \& Camerer, C. 1998. Not so different after all: A cross-discipline vicw of trust. Academy of Management Revieze, 23: 393-421.

Schepel, H. 2006. European regulation of consumer product. Common Market Laze Revieze, 43 : $1789-1791$.

Smith, N. C., Thomas, R.J., \& Quclch, J. A. 1996. A stratcgic approach to managing product recalls. Harvard Business Review, Scptember-Octobcr: 102-112.

Tam, O. K. 2002. Ethical issucs in the cvolution of corporate governance in China. Joumal of Business Ethics, 37: 303-320.

Tecce, D. J., Pisano, G., \& Shuen, A. 1997. Dynamic capabilities and strategic management. Strategic Management Journal, 18: 509-533.

Wright, P. C., Szeto, W. F., \& Lce, S. K. 2003. Ethical perceptions in China: The reality of business ethics in an international context. Management Decision, 41: 180-189. 
Yadong Luo (yluo@exchange.sba.miami.edu) is the Emery M. Findley Distinguished Chair of Graduate Business Studies, Chairman of the Department of Management, and Professor of International Business and Strategy in the School of Business, the University of Miami. He has authored 15 books, more than 130 referred journal articles and over 100 other publications. His recent research focuses on global strategy and international management in emerging economies.

Manuscript received: January 9, 2008

Final version accepted: March 13, 2008

Accepted by: Marshall W. Meyer 